\title{
The Potential of Nano-Porous Surface Structure for Pain Therapeutic Applications: Surface Properties and Evaluation of Pain Perception
}

\author{
Ching-Zong Wu ${ }^{1,2,3,+}$, Ling-Chuan Hsu ${ }^{1,+}{ }^{\dagger}$ Hsin-Hua Chou ${ }^{1,4}$, Sanne Barnkob ${ }^{5}$, Tobias Eggert ${ }^{5}$, \\ Pernille Lind Nielsen ${ }^{5}$, Roger Young ${ }^{1}$, Lene Vase ${ }^{6}$, Kelun Wang ${ }^{7}$, Peter Svensson ${ }^{5,8}$, \\ Keng-Liang Ou ${ }^{9,10,11,12, *}$ and Lene Baad-Hansen ${ }^{5}$ \\ 1 School of Dentistry, College of Oral Medicine, Taipei Medical University, Taipei 110, Taiwan; \\ chinaowu@tmu.edu.tw (C.-Z.W.); vincents.dent@gmail.com (L.-C.H.); hhchou@tmu.edu.tw (H.-H.C.); \\ stingzard@gmail.com (R.Y.) \\ 2 Department of Dentistry, Taipei Medical University Hospital, Taipei 110, Taiwan \\ 3 Department of Dentistry, Lotung Poh-Ai Hospital, Yilan 265, Taiwan \\ 4 Dental Department of Wan-Fang Hospital, Taipei Medical University, Taipei 116, Taiwan \\ 5 Section of Orofacial Pain and Jaw Function, Department of Dentistry and Oral Health, Aarhus University, \\ 8000 Aarhus, Denmark; b_sanne@yahoo.dk (S.B.); eggert-t@hotmail.com (T.E.); \\ nolle16@hotmail.com (P.L.N.); peter.svensson@odont.au.dk (P.S.); lene.hansen@odont.au.dk (L.B.-H.) \\ 6 Department of Psychology and Behavioral Sciences, Aarhus University, 8000 Aarhus, Denmark; \\ lenevase@psy.au.dk \\ 7 The Faculty of Medicine, Department of Health Science and Technology, Center for Sensory-Motor \\ Interaction, Aalborg University Hospital, 9100 Aalborg, Denmark; kelun@hst.aau.dk \\ 8 Department of Dental Medicine, Karolinska Institute, 14157 Huddinge, Sweden \\ 9 Department of Dentistry, Taipei Medical University-Shuang Ho Hospital, New Taipei City 235, Taiwan \\ 10 Department of Oral Hygiene Care, Ching Kuo Institute of Management and Health, Keelung 203, Taiwan \\ 11 Biomedical Technology R \& D Center, China Medical University Hospital, Taichung 404, Taiwan \\ 12 3D Global Biotech Inc. (Spin-off Company from Taipei Medical University), New Taipei City 221, Taiwan \\ * Correspondence: klouyu@gmail.com.tw \\ + Authors contribute equally.
}

Received: 18 May 2020; Accepted: 26 June 2020; Published: 1 July 2020

check for updates

Featured Application: The potential application of the work is in the area of acupuncture therapy. The study focuses on the nanostructured surfaces to stimulate connective tissue interaction at the neurological sites for pain therapy.

\begin{abstract}
The objective of this study was to evaluate the biomaterial properties of nano-modified surface acupuncture needles and the effect of such needles on human pain perception by using pressure pain threshold (PPT) measurements. It is known that changing a material's surface nano-topography or nanostructure has strong effects on its physical, chemical, and biological surface properties. However, there is no information in the literature about the stimulation characteristics of acupuncture needles with nano-topography or nanostructured surfaces. Based on the knowledge on nanostructured surfaces, it may be possible to potentiate the effects of acupuncture needle stimulation. The pressure pain sensitivity of the masseter muscle in the orofacial region was studied in 21 healthy volunteers in two randomized, double-blinded sessions: an active session of manual acupuncture manipulation with nano-modified surface needles, and an inactive session of sham acupuncture stimulation to control for possible placebo effects. Three acupuncture points were selected from classical Chinese medicine literature: LI4 (Hegu) on the hand, ST6 (Jiache) on the lower masseter region, and ST7 (Xiaguan) on the upper masseter region. PPT measurements, perceived sensations, and pain from the acupuncture were recorded. The results showed discrete yet significant differences in PPT values between the active and inactive acupuncture treatments and significantly higher pain
\end{abstract}


scores from active acupuncture stimulation than from sham acupuncture. These results indicate subtle but significant effects of acupuncture stimulation with nano-modified surface needles, compared to sham acupuncture in healthy participants.

Keywords: acupuncture; nano-modified surface; pressure pain threshold; orofacial pain

\section{Introduction}

Acupuncture is a complementary therapy applied widely in pain management. The number of reports on its therapeutic effects in various orofacial pain conditions has been on the rise [1]. However, a major obstacle in conducting these studies is to adequately control for placebo effects [2]. The present study was designed to investigate the effects of acupuncture on orofacial musculoskeletal pain sensitivity, and was specifically targeted towards the masseter muscle, which is often involved in temporomandibular disorders (TMDs) [3-6]. The results of our previous study indicated that the condyle was asymmetrical during jaw closing, and that both the condyle and disc were slightly asymmetrical during jaw opening in patients with TMD [7]. One-third of adults are reported to have symptoms of TMDs, which include headaches, joint pain, and clicking or muscle tenderness $[8,9]$. Many therapies have been applied for TMD management, such as self-care after mirror experiences, intra-oral devices, night-time biofeedback, and complementary acupuncture therapy [10,11].

According to the classical Chinese medicine literature, a physiological phenomenon called "Deqi" is required to achieve good therapeutic outcomes from acupuncture treatment $[12,13]$. The sensations described by the patients can involve dullness, heaviness, distension, numbness, and aches during the Deqi phase of the acupuncture $[14,15]$. The classical Chinese medicine literature, Huangdi Neijing (Huangdi's canon of medicine), states that Deqi should be felt by the acupuncturists who also need to concentrate in order to hold it. Thus, the process of Deqi with needles is experienced by both patient and acupuncturist. The acupuncturist feels an increase in resistance while manipulating the needles (needle grasping), and the sensation is described as tense, tight, or heavy $[15,16]$. Needle grasping (Deqi) is thought to be important for clinical efficacy, according to the traditional Chinese medicine theory, and there is some scientific support for this claim. Langevin's team investigated the physiological changes during the sensations of Deqi. They observed connective tissue grasping and winding around the inserted needle during the rotational manipulation of acupuncture needles [12]. Their work also showed that the needle grasping phenomenon necessitated more pull-out force to withdraw the needle, and increased the tissue volume around the needle insertion site $[17,18]$. The needle grasping or tissue winding induced by needle movements stimulates the local tissues, such as the connective tissue, thereby delivering a mechanical signal that leads to downstream effects $[19,20]$. This includes a change in the gene expression or alteration of the composition of the extracellular matrix. Connective tissue is the main tissue type affected by needle manipulation. The winding of the connective tissue is believed to be the reason for local, remote, and long-term therapeutic effects of acupuncture [21]. To summarize Langevin's research, acupuncture creates changes in the connective tissue, which impact the body at the cellular level via mechano-transduction [20]. These mechanical signals may also stimulate the endocrine system to release endogenous opioids, which act as analgesics of specific neurological sites. This may be the biochemical mechanism by which acupuncture blocks the nociceptive inputs and transmission, thereby eliciting an analgesic response [16,22,23].

It is well known that changing a material's surface nano-topography or nanostructure has strong effects on its physical, chemical, and biological properties [24-27]. The nano-topography of the surfaces has also been demonstrated to be able to alter gene expression, facilitate or direct stem cell differentiation, induce changes in the cell morphology, and stimulate the proliferation and spreading of different cell types [28-32]. Such changes in surface properties have been extensively used in dental, orthopedic, and other biomedical applications. However, there is no information in the literature 
about the stimulation characteristics of acupuncture needles with nano-topography or nanostructured surfaces. Based on the knowledge on nanostructured surfaces, it may be possible to potentiate the effects of acupuncture needle stimulation. Hence, the present double-blinded placebo-controlled cross-over study was designed to investigate the surface properties of nano-modified SS acupuncture needles and their effect on the pressure pain sensitivity of the masseter muscle. The present study was conducted in collaboration with Taipei Medical University, Taiwan and Aarhus University, Denmark.

\section{Materials and Methods}

\subsection{Materials Preparation}

The diode-pumped solid-state (DPSS) laser with neodymium-doped yttrium orthovanadate (Nd: $\mathrm{YVO}_{4}, \lambda=335 \mathrm{~nm}$ ) laser source system (BLS1, Titan Electro-Optics Inc., Taipei, Taiwan) was used to modify needles in this study. The polished needle-type (Ø0.3 $\mathrm{mm} \times 50 \mathrm{~mm}$ ) and disc-type $(\varnothing 10 \times 2 \mathrm{~mm})$ austenite SUS $304 \mathrm{SS}$ samples were modified under $1 \mathrm{~W}$ laser power and $100 \mathrm{~mm} / \mathrm{s}$ scanning speed for human testing and surface property analysis, respectively. The unmodified SS (U-SS) needles (for sham acupuncture in the present study) and nano-modified SS (Nano-SS) needles were cleaned in ethanol (Sigma-Aldrich Inc., Taipei, Taiwan) for $15 \mathrm{~min}$ in an ultrasonic bath, followed by air drying before analysis.

\subsection{Surface Property Evaluation of the Modified Needle Samples}

Atomic force microscopy (AFM; Mobile S, Nanosurf Inc., Liestal, Switzerland) and scanning electron microscopy (SEM; JSM-6500F, JEOL Inc., Tokyo, Japan) were performed to analyze the surface morphology and roughness of the Nano-SS sample (disc-type). Phase identification and crystallinity analysis were carried out in an X-ray diffractometer (XRD; Rigaku 2200, Rigaku Inc., Tokyo, Japan), with $\mathrm{CuK} \alpha 1$ radiation operated at $50 \mathrm{kV}$ and $250 \mathrm{~mA}$. Wettability examination was performed using the sessile drop method by a GBX DGDDI contact angle goniometer (Drôme, France) using liquid deionized water [33]. Contact angle measurements were performed using at least five drops for each sample in order to reduce variation.

\subsection{Finite Element Analysis (FEA)}

The computer-aided research part was focused on investigating homogeneous and isotropic effect of acupuncture needle treatment on the skin. Von Mises stresses for the needles were calculated on a personal computer (Dell Precision T3500, 12.0 GB RAM, INTEL (R) Xeon (R) CPU), using the ANSYS 12.1 version (ANSYS Inc., Canonsburg, PA, USA) program. The linear elastic properties of the skin structures in the volumes were calculated. Model convergence was set at a $2 \%$ overall mesh size. Mesh refinement was used for major interfaces such as the needle-skin interface. The average number of nodes and elements in each model was 14,587 and 9745, respectively. A tetrahedral element was used, i.e., each side had a mid-side node and each node had three degrees of freedom. With respect to boundary conditions in models, the skin model was fixed at the bottom and the needle was inserted into the skin model $10 \mathrm{~mm}$. For the present research, the sites were grouped into U-SS group and Nano-SS group based on the treatment of the material used and the Von Mises stresses of the needles and skin were studied.

\subsection{Participants}

The study included 21 healthy participants (seven men and 14 women) with ages ranging from 19 to 32 years and comprised 20 Caucasians and one Asian. The beliefs and opinions of the participants about acupuncture did not influence the inclusion in the study and none of the participants had any prior acupuncture experience. Inclusion criteria included a good self-reported health status without any orofacial pain conditions. The Research Diagnostic Criteria for TMD was performed in all subjects before inclusion to rule out painful TMD. Exclusion criteria were: painful temporomandibular 
disorders (temporomandibular joint click and crepitation without pain was allowed), any critical physical or mental disorders, intake of any medicine that affects the central nervous system, and any prior nerve damage affecting the orofacial area. All participants signed a statement of informed consent and were paid a compensation of 28 Euros (200 DKK) each for participating in the study.

\subsection{Study Design}

The project was approved by the Local Ethics Committee (Central Denmark region). The study was carried out at the Department of Dentistry, Aarhus University, Denmark. The participants were randomly assigned to receive the active (Nano-SS needle Figure $1 \mathrm{a}, \mathrm{b}$ ) or the inactive (sham needle Figure $1 \mathrm{c}, \mathrm{d}$ ) acupuncture in the first session. After approximately 10 days, each subject received the intervention, which was the opposite of that received in the first session. Each acupuncture session lasted up to $30 \mathrm{~min}$, including $20 \mathrm{~min}$ of acupuncture treatment with three acupuncture needle stimulations and repeated PPT measurements at three sites: (1) the masseter muscle on the same side as the dominant hand, (2) the masseter muscle on the non-dominant hand side, and (3) the thenar muscle of the dominant hand at four time points: (a) before acupuncture, (b) immediately after needle insertion and stimulation, (c) after 10 min of acupuncture and repeated stimulation, and (d) after a third stimulation and subsequent removal of the acupuncture needles. The PPT test sites were chosen in order to demonstrate local as well as generalized effects.

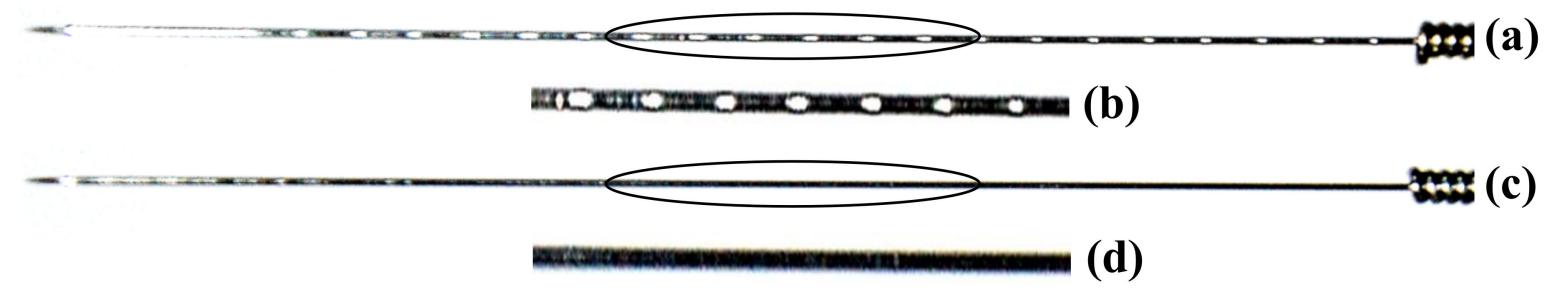

Figure 1. Comparison of acupuncture needles: (a) Nano-SS needle, (b) a higher magnification image taken from the black circle in (a) showing the laser-modified surface feature, (c) U-SS needle, and (d) a higher magnification image taken from the black circle in (c) showing the surface without any modification feature.

The stimulation by the acupuncture needles was performed as manual unidirectional rotational manipulation without any thrusting during the procedure. At the beginning of the acupuncture procedure, the subject first identified their dominant hand to determine the side of the face for needle insertion. The active or sham needles were then applied to the participant beginning from the distal point (LI4) (non-dominant hand), and moving on to the facial points ST6 and ST7 (dominant hand side). In the active acupuncture session, the participants received the true penetrative needles (depth of insertion $10 \mathrm{~mm}$ ) into the skin and underlying tissues. Manual manipulations with 15 revolutions in clockwise direction were performed for each point. In the sham acupuncture session, the participants received sham needles with blunted tips specifically designed to prevent skin penetration. The sham needles were designed to be applied with a plastic guiding tube (Figure 2). The sham needles were $10 \mathrm{~mm}$ shorter in length than the true penetrative needles; hence, the needle tip barely touched the superficial epidermis, without any actual penetration. Neither the participants nor the PPT examiner was able to identify the treatment they received, based on the appearance of the needles. The active needles were also applied through a plastic tube in order to preserve the integrity of the double blinded nature of the study. The acupuncturist also maintained the blinding by mimicking the needle stimulation procedure in the sham acupuncture session. The needles were retained in the body for $20 \mathrm{~min}$ with manual manipulation every $10 \mathrm{~min}$. The acupuncturist manipulated the needles $10 \mathrm{~min}$ after the insertion, after which the blinded investigator immediately performed the PPT measurements. The acupuncturist performed the second manipulation $20 \mathrm{~min}$ after the initial needle insertion and then removed the needles. The investigator repeated the PPT measurements. The participants were 
subjected to the same experimental procedure and investigation by the same study personnel during the second visit.

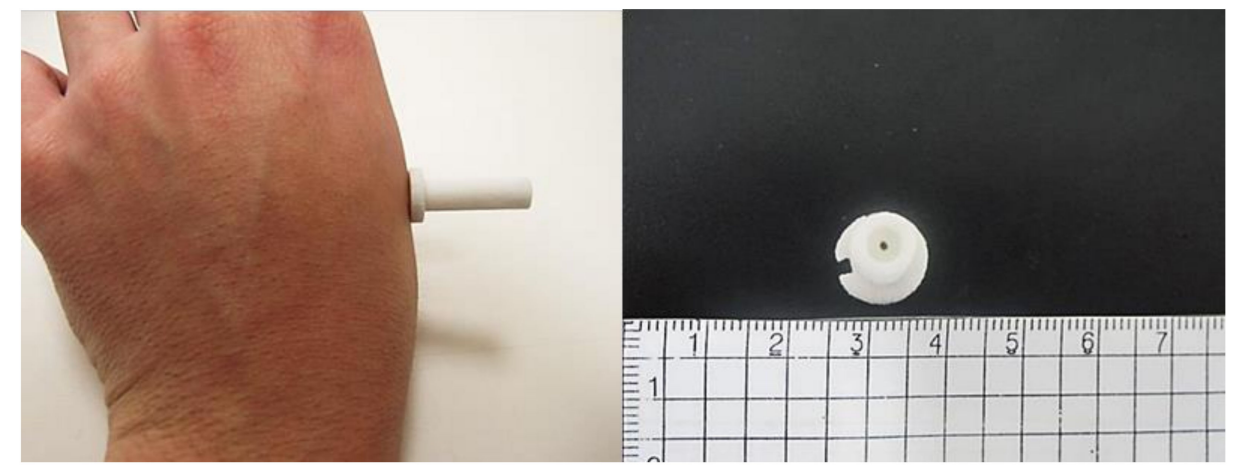

Figure 2. Inactive acupuncture guiding tube. Concaved needle handle anchor on the top with two insertion site markers on the side and adhesive button part.

Prior to the beginning of the first session, participants were requested to complete a form with personal information, health status, and a series of questions regarding their knowledge of acupuncture therapy. The subjects were asked about their belief of the beneficial effects of acupuncture and any expectation they had from the treatment. Immediately after each needle insertion, the investigator asked the participants whether he/she felt anything (yes/no). The participants were then asked to rate the sensations evoked by the acupuncture needle on a numerical rating scale (NRS) of $0-10$ (0 being no pain and 10 being the highest imaginable pain). Furthermore, the participants were asked to specify the sensation as "sharp pain", "pricking", "tingling", or "other sensation". The participant's and the investigator's thoughts, as to which needle (active or sham) was used, were recorded after needle insertion and at the end of the session. Participants were advised to take a light meal before they came to the session to minimize the possibility of side effects such as fainting, dizziness or discomfort. During the entire experiment, the investigator carefully monitored the participant's condition to ensure safety and efficiency of the experiment.

\subsection{Acupuncture}

Based on the Chinese medicine literature on facial pain (targeted on trigeminal neuralgia distribution), ST6 Jiache and ST7 Xiaguan points were selected for the activation of the masseter muscle on the side of the dominant hand. These two acupuncture points coincide with the distribution of the maxillary nerve branches. The distal point LI4 Hegu is located contralateral to the dominant side and subjected to the same acupuncture manipulations as those of the points on the face. Both the active and inactive needles were concealed inside plastic guiding tubes before the treatment began. The guiding tube was made opaque and there were two markers at the base of the tube to ensure that the method of insertion was accurate.

\section{7. $P P T$}

A standardized PPT measurement using an electronic pressure algometer (Somedic Inc., Sösdala, Sweden) was performed at four different time points: (1) at baseline, (2) immediately after the first insertion and manipulation of the acupuncture needle, (3) $10 \mathrm{~min}$ after needle insertion (after the second manipulation), and (4) immediately after the third-needle stimulation and subsequent needle withdrawal. All PPT measurements were performed according to the standard research protocol established by the German Research Network on Neuropathic Pain (DFNS) [34-36]. The PPT was measured in triplicate on both masseter muscles (between ST6 and ST7) and on the thenar on the dominant hand (the side opposite to that of the LI4 acupuncture point). The pressure algometer had a rubber tip with a contact area of $1 \mathrm{~cm}^{2}$, which was pressed against the skin on the test region with a 
gradual increase of the pressure of $30 \mathrm{kPa} / \mathrm{s}$. The test subject notified the investigator when the pressure became just slightly painful by pressing a stop button.

\subsection{Statistics}

Data are presented as mean \pm SD or as percentages (\%). Three (one for each PPT test site) two-way Analyses of Variance (ANOVAs) with acupuncture session type (active vs. sham) and PPT measurement time as factors were performed. Where appropriate, Tukey's Honestly Significant Difference (HSD) tests with corrections for multiple comparisons were performed for post hoc analyses. McNemar's tests were performed to compare frequencies of sensation of needle insertion between sessions. Effect of the blinding procedure was evaluated by quantification of the proportion (\%) of participants and examiners, who were able to correctly identify active or placebo needles. Differences were regarded as significant when $p<0.05$. Statistical analyses were performed by using the STATISTICA statistical software (StatSoft 13 version, Hugecon Inc., Kaohsiung, Taiwan).

\section{Results}

\subsection{Nano-Modified Surface Properties}

Figure 3a shows the SEM image of a Nano-SS needle sample. Laser modification resulted in a wave like structure on the surface. A higher magnification SEM image of the white circle area in the Nano-SS sample shows the presence of nano-porous structures on the surface of the Nano-SS sample (Figure 3b). Figure 3c shows the XRD patterns from the U-SS and Nano-SS samples. All the peaks were analyzed using the database from the Joint Committee on Powder Diffraction Standards. Only typical austenite phase $(\gamma)$ peaks were detected in the U-SS and Nano-SS samples. The crystalline structure of the $\gamma$ phase belongs to face centered cubic structure. No other precipitates or intermetallic compounds could be found on the surface of the Nano-SS sample. According to the AFM observation, the surface roughness (represented as root mean square) of the nano-porous structure was about $18.6 \mathrm{~nm}$ (Figure 3d). The contact angle of the U-SS and the Nano-SS samples is presented in Figure 3e. The Nano-SS needle sample exhibited a more hydrophilic surface $\left(\sim 31^{\circ}\right)$ than the U-SS sample $\left(\sim 65^{\circ}\right)$ [37]. Thus, a hydrophilic wave like surface layer with nano-porous structure was formed on the surface of the Nano-SS sample.

Figure 4a shows the stress distribution for the Nano-SS and U-SS models on the skin at $1 \mathrm{~s}$. The maximum stress varied from 35.2 MPa to $85.3 \mathrm{MPa}$ in all models, as shown in Figure $4 \mathrm{~b}$. In the Nano-SS group, the stress (85.3 MPa) was larger than the maximum stress of $78.9 \mathrm{MPa}$ in the U-SS group at $1 \mathrm{~s}$. The stress on the skin while using treated needles was larger than that exerted by the needles without surface treatment. However, the stress patterns in both models were similar to each other. Analysis of the present study indicated that stresses were induced by the needle.

(a)

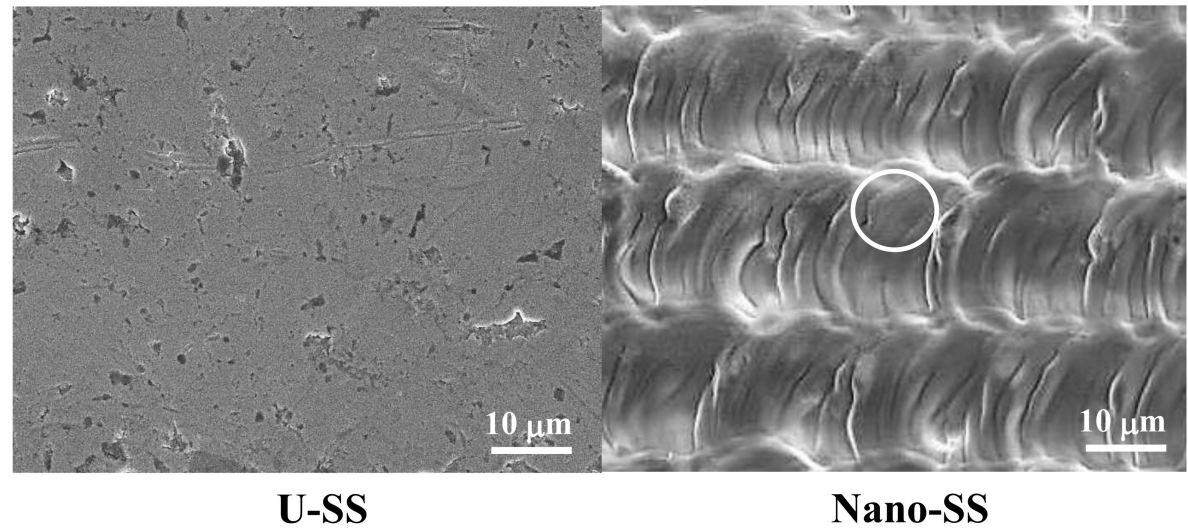

Figure 3. Cont. 
(b)

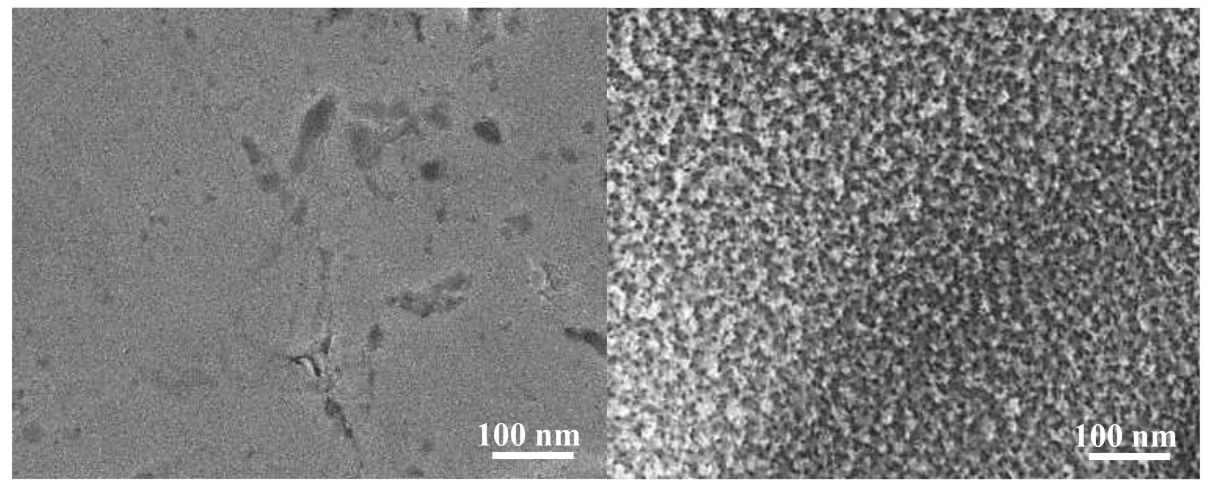

U-SS

Nano-SS

(c)

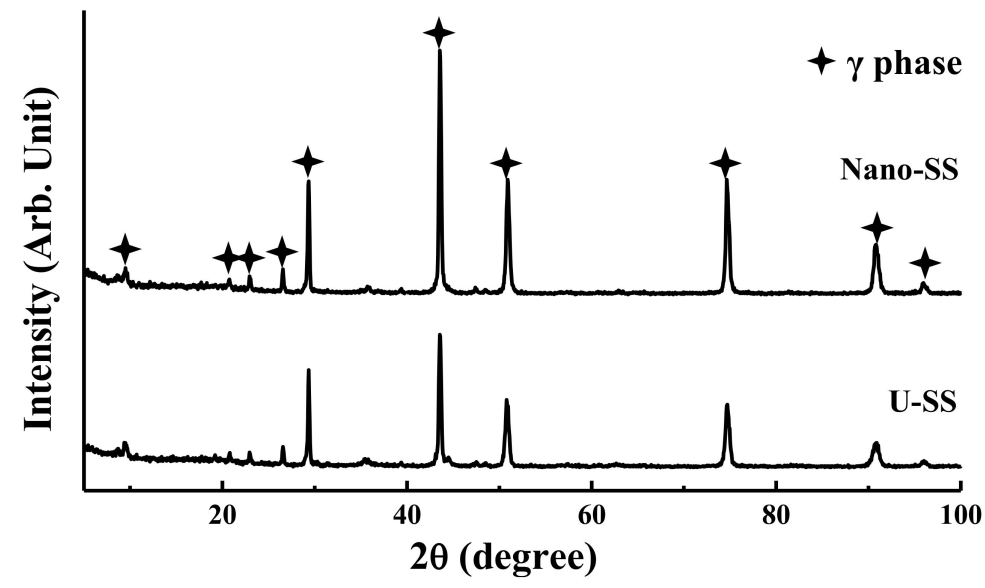

(d)



U-SS

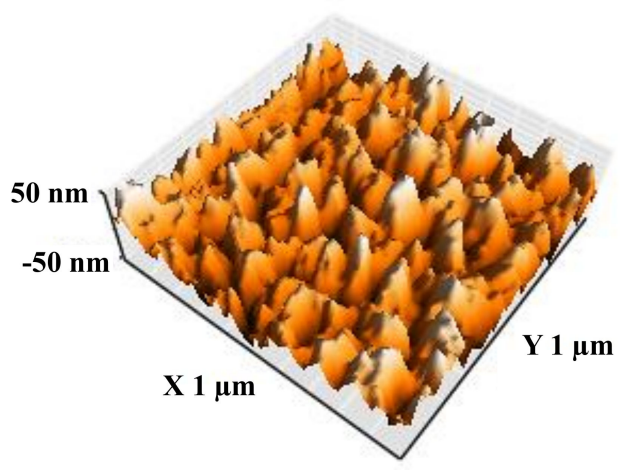

Nano-SS

Figure 3. Cont. 


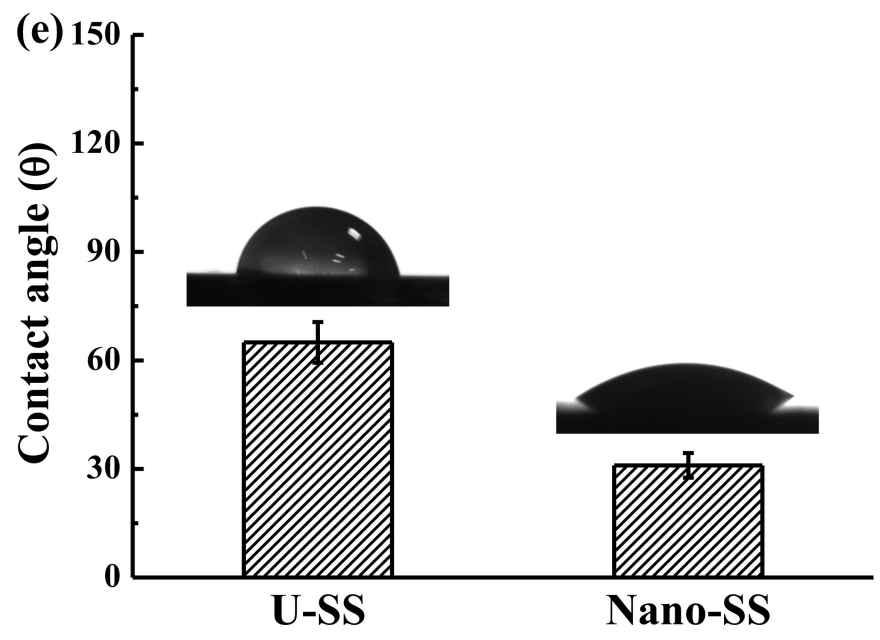

Figure 3. Characteristics of the U-SS and Nano-SS samples: (a) SEM micrographs, (b) a higher magnification of SEM micrograph which taken from the white circle area in (a), (c) XRD patterns, (d) AFM images, and (e) wettability evaluation.
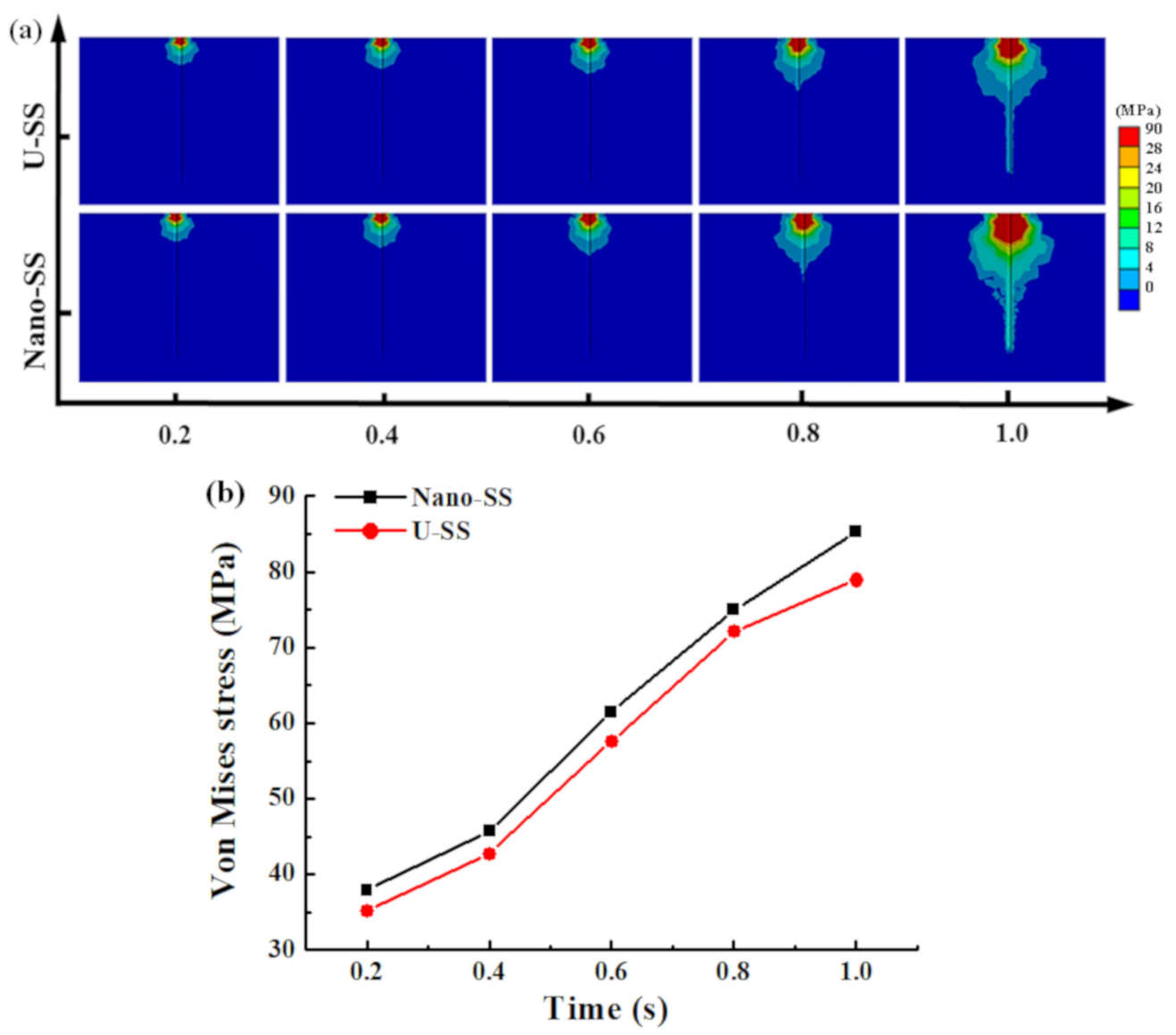

Figure 4. (a) Stress distributions of Nano-SS and U-SS in the skin, and (b) the highest stress for $1 \mathrm{~s}$.

\subsection{Effect of Nano-Modified Surface Acupuncture on Human Pressure Pain Sensitivity}

None of the 21 subjects reported any major or minor adverse effects after the acupuncture treatments and all subjects completed the two acupuncture sessions without dropping out. The penetration of the needles through the skin was felt in both sessions by the volunteers. Neither of the two sessions (active vs. placebo needle) on the dominant hand side masseter muscle had a significant effect on the PPT measurements $(p=0.428)$. However, there was a significant change over time $(p=0.011)$ 
and a tendency towards a significant interaction between session and time $(p=0.081)$. A focused post hoc analysis of the tendency showed that $10 \mathrm{~min}$ after needle insertion, PPT in the active session was significantly increased (decreased pressure pain sensitivity) compared with the placebo session $(p=0.006)$. There was no statistically significant change from baseline in either session $(p>0.239)$.

No significant main effects of session or time were detected in PPTs from the masseter muscle contralateral to the dominant hand (Session: $p=0.413$; Time: $p=0.969$ ) or from the thenar muscle (Session: $p=0.407$; Time: $p=0.846$ ). No significant interactions between factors were found at these two test sites $(p>0.227)$.

The thenar muscle showed higher PPTs than the facial regions $(p<0.001)$. There were no differences in PPT values of masseter muscles between sides $(p=0.940)$ (Table 1).

Table 1. Presentation of means (SD) of pressure pain thresholds (PPT in $\mathrm{kPa}$ ) of the three test sites at different time points. The values in bold indicates a significant difference from placebo. Dom $=$ Dominant hand side masseter muscle, Non $=$ Non-dominant hand side masseter muscle.

\begin{tabular}{|c|c|c|c|c|c|c|c|c|}
\hline \multirow[b]{2}{*}{ Site } & \multicolumn{4}{|c|}{ Inactive } & \multicolumn{4}{|c|}{ Active } \\
\hline & Baseline & Immediately & $10 \mathrm{~min}$ & $20 \mathrm{~min}$ & Baseline & Immediately & $10 \mathrm{~min}$ & $20 \mathrm{~min}$ \\
\hline \multirow{2}{*}{ Dom } & 195.1 & 175.9 & 190.3 & 200.7 & 203.7 & 195.1 & 220.9 & 204.1 \\
\hline & $(74.7)$ & $(62.9)$ & $(70.4)$ & $(72.7)$ & (71.3) & $(76.8)$ & $(88.4)$ & $(76.1)$ \\
\hline \multirow{2}{*}{ Non } & 191.4 & 179.6 & 188.7 & 184.3 & 196.7 & 203.2 & 198.7 & 204.5 \\
\hline & $(77.7)$ & (69.6) & $(73.0)$ & (73.3) & $(77.8)$ & (78.3) & $(81.2)$ & $(84.5)$ \\
\hline \multirow{2}{*}{ Thenar } & 294.0 & 312.5 & 285.5 & 286.2 & 321.5 & 319.9 & 320.5 & 326.1 \\
\hline & $(132.0)$ & $(131.4)$ & $(136.6)$ & $(174.6)$ & (166.8) & (160.6) & $(169.3)$ & (194.7) \\
\hline \multirow{2}{*}{ Total } & 226.8 & 222.7 & 221.5 & 223.7 & 240.6 & 239.4 & 246.7 & 244.9 \\
\hline & $(108.0)$ & (111.9) & $(106.8)$ & $(123.7)$ & $(126.1)$ & (124.5) & $(129.4)$ & $(140.5)$ \\
\hline
\end{tabular}

The analyses of the sensations evoked by acupuncture needles showed that the sham acupuncture needle was felt by $57.1 \%$ of the participants on the hand site, $66.7 \%$ on the lower masseter site and $76.2 \%$ on the upper masseter site. The active needles were felt by $87.7 \%$ on the hand site, $85.7 \%$ on the lower masseter site and $81.0 \%$ on the upper masseter site. From the McNemar's tests, it was found that the nano-modified acupuncture needles were felt by more participants than the sham needles for all sites $(p<0.039)$ (Figure 5).

The mean perceived intensity of the acupuncture evoked pain on the 0-10 NRS in the sham acupuncture session was $0.8( \pm 1.1)$ in the distal insertion site (hand), $1.1( \pm 1.0)$ in the lower masseter region and $1.2( \pm 1.0)$ in the upper masseter region. In the active acupuncture session, the mean perceived intensity of the acupuncture evoked pain was $2.7( \pm 2.0)$ on the distal insertion site (hand), $3.4( \pm 2.0)$ in the lower masseter region and $3.1( \pm 2.5)$ in the upper masseter region. Hence, the active acupuncture in the three insertion sites (Hand, Lower masseter and Upper masseter) evoked statistically higher levels of pain than the sham acupuncture $(p<0.05)$.

In the first session, $28.6 \%$ of the participants correctly identified the treatment they received while $23.8 \%$ were wrong about the treatment they received and $47.6 \%$ indicated that they did not know. In the second session, more participants were able to identify the treatment they received (42.9\%), but $38.1 \%$ still did not know. When the data from both sessions were combined, $33.3 \%$ of the subjects were truly blinded and only $14.3 \%$ were able to identify correctly, the treatment they received in both sessions. In the first session, the blinded investigators guessed the treatment correctly for $52.4 \%$, wrongly for $28.6 \%$ and could not make a guess for $19.1 \%$ of the participants. In the second session, the investigators guessed correctly for only $9.5 \%$ of participants and could not make a guess for the remaining $90.5 \%$ of participants. 

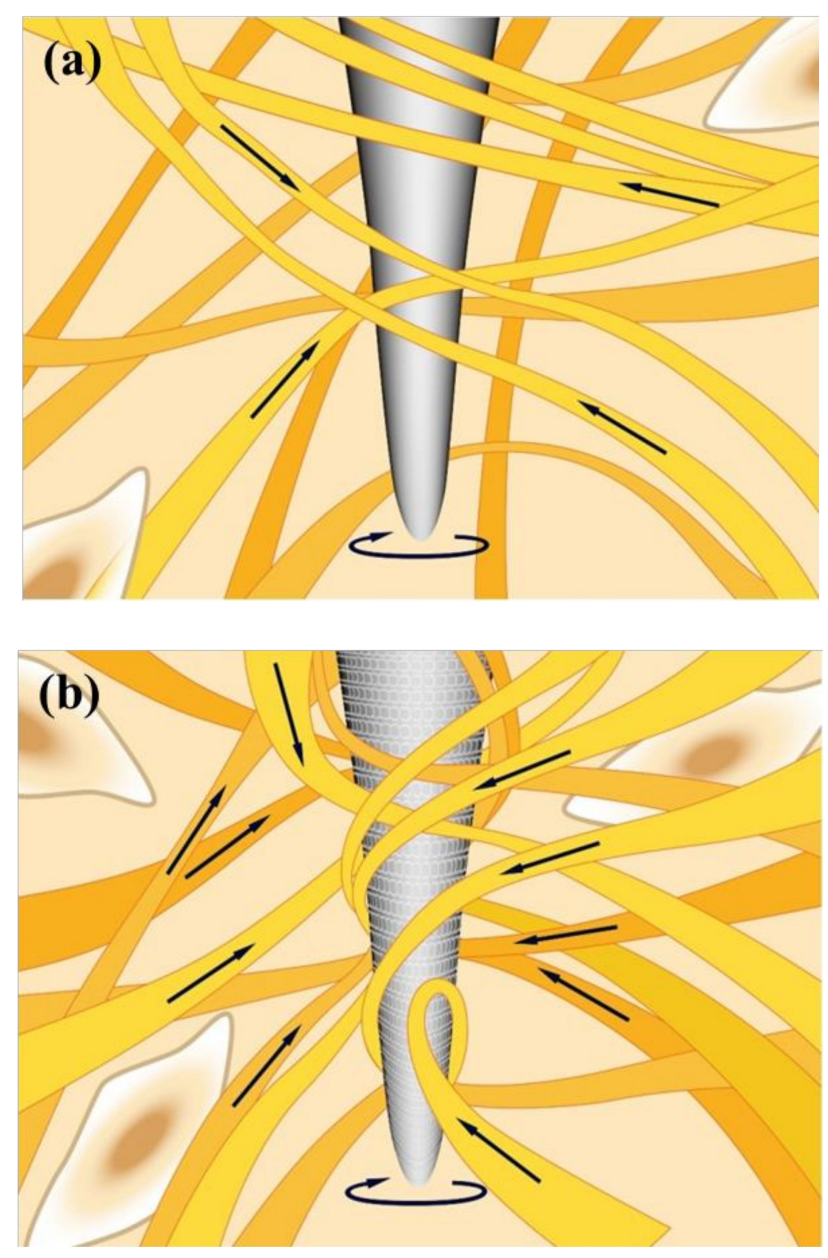

Figure 5. The nano-modified acupuncture needle has the ability to increase tissue winding effect due to the increased surface area on the needle shaft: (a) tissue winding effect of the U-SS needle and (b) tissue winding effect of the Nano-SS needle.

\section{Discussion}

The main finding of this study was that no overall significant differences between active and sham acupuncture, as measured by the PPTs, could be detected in healthy participants. However, there was a modest tendency towards a small increase in PPT (reduced pressure pain intensity) for the masseter muscle of the acupuncture needle side in the active session as compared with that in the sham session. As shown in Table 1, the minor difference between active and sham needle sessions of the PPT measurements may be seen as a validation of the earlier reported placebo-effect of acupuncture therapy $[38,39]$. The sham needle may have stimulated the superficial epidermis. Since the sham needle did not penetrate the subject's skin and into the acupoint, it did not reach our stimulation goal, Deqi, in the study. Therefore, a possible explanation could be that the participants in the sham session might have experienced peripheral sensory stimulation and in some cases even a sharp pain perception, even though the needles did not exactly penetrate the skin [40,41]. It is certainly difficult to insert acupuncture needles without evincing any sensory stimulation. Although the sham needle is short and blunt, a very gentle touch from the needle tip may still exert an effect [42,43].

The active needles induced significantly more frequent and intense sensations than the sham needles. This can probably be attributed to the depth of needle insertion, but also partly to the increased surface area of the Nano-SS needle, which provides more space for tissue attachments leading to greater stimulation. As compared to smooth surfaces (U-SS needle), the textured needle shaft surfaces of the Nano-SS needle present more surface area for interaction with and stimulation of the tissues. It can be expected that the textured surface has a positive influence on connective tissue grasping and winding, 
which may result in a better stimulation result (Figure 5) [16,17,44-46]. The contact area of the needle has a lot to do with the stimulation effect of the acupuncture manipulation techniques. The technique of rotational manipulation increases needle pull out forces, when acupuncture needles are inserted into the connective tissue layer (unidirectional and bidirectional). The winding of connective tissue because of the acupuncture manipulation may transduce a series of mechanical signals and stimulate endocrine physiological events $[20,47,48]$. Finite element method detected hard stimulation in the group receiving acupuncture with surface treated needles. The discontinuous structure induced lots of stress confusing to stimulate the neural pain sensation to promote the clinical treatment effect $[49,50]$.

FEA has been used for decades in mechanical engineering and design. In the dental field, models have been used to describe the stresses and strains in different structures, such as the TMJ, dentition, and facial skeleton. Biomechanical models of the human masticatory system using the FEA program were not perfect but are based on various assumptions and simplifications. Moreover, it was difficult to compare the earlier studies clearly because of the differences in muscle force, material setting, mesh structure, and other constraints. The result of FEA was also very difficult to compare to a real model because of the mechanical and physical properties of the model in the biological field. The human organs have a very complex structure. For example, the condyle cartilage layer is composed mainly of large proteoglycans such as versican and aggrecan [51]. In general, large proteoglycans are more suited to resisting compressive force than articular disc which is composed mainly of collagen fibers [52]. An accurate representation of the condyle cartilage layer in TMJ finite element models was of vital importance, but it was very difficult to achieve in the computer-aided program. Therefore, simplification was a common way to study. Mechanical forces, temperature and electricity have been applied to a variety of nerve stimulation including different tissues [53-55]. These studies have led to new insights into how tissue to transmit signals by mechanical stimulation. Mechanical stimulation is also a kind of substrate for cell adhesion, growth, and differentiation [56]. During bone remodeling or wound healing, a stress simulation mechanism must start to enhance the response of gene expression. These advances have significantly increased our understanding of the process of mechanical transductions inducing stimulation using the acupuncture.

The nano-porous structures of the Nano-SS needle probably plays an important role in increasing the surface area, which leads to more space for connective tissue interaction at the neurological sites during the acupuncture. However, more clinical research on the influence of nano surface and nanostructures of acupuncture needles is clearly needed to better understand their potential advantages compared with conventional needles. It should also be mentioned that acupuncture with surface modified needles in this study did not result in any significant complications. None of the subjects reported any adverse effects or major concerns during and after the sessions. Owing to the small sample size, the study findings must be interpreted cautiously and the possible effects on clinical pain should be investigated further.

\section{Conclusions}

A hydrophilic wave-like surface layer with nano-porous structures was formed on the surface of the modified acupuncture needles used in the present study. The results showed subtle yet significant differences in PPT measurements between the active and sham acupuncture groups, and significantly higher pain scores from active acupuncture stimulation than from sham acupuncture. These results indicate subtle effects of acupuncture with nano-modified needles compared to effects of shame acupuncture in healthy participants. Further studies in patients with clinical pain are needed.

Author Contributions: For this research article, C.-Z.W. and L.-C.H. were the main authors responsible for the original draft. L.-C.H. was also responsible for the software analysis along with H.-H.C., R.Y. contributed to the investigation. S.B., T.E. and P.L.N. were responsible for the data collection. L.V. and K.W. contributed to the validation. P.S., L.B.-H. and K.-L.O. were responsible for the study design, supervision, and manuscript review \& editing. All authors have read and agreed to the published version of the manuscript. 
Funding: The authors are grateful to the Biomate Medical Devices Technology co., ltd and ANMC Healthcare, Inc. for their support with experimental devices and testing instruments. This study is also supported in part by Lo-Hsu Foundation Lotung Poh-Ai Hospital (104-E126) and the Danish Dental Association. Special thanks are extended to the Department of Dentistry and Oral Health, Aarhus University, Denmark and 3D Global Biotech Inc., Taiwan, for their skillful technical assistance.

Conflicts of Interest: The authors declare no conflict of interest in this work.

\section{References}

1. List, T.; Axelsson, S. Management of TMD: Evidence from systematic reviews and meta-analyses. J. Oral Rehabil. 2010, 37, 430-451. [CrossRef] [PubMed]

2. Vase, L.; Baram, S.; Takakura, N.; Yajima, H.; Takayama, M.; Kaptchuk, T.J.; Schou, S.; Jensen, T.S.; Zachariae, R.; Svensson, P. Specifying the nonspecific components of acupuncture analgesia. Pain 2013, 154, 1659-1667. [CrossRef] [PubMed]

3. Welsh, D.; Hengerer, A.S. The diagnosis and treatment of intramuscular hemangiomas of the masseter muscle. Am. J. Otolaryngol. 1980, 1, 186-190. [CrossRef]

4. Lao, L. Acupuncture techniques and devices. J. Altern. Complement. Med. 1996, 2, 23-25. [CrossRef]

5. Mupparapu, M. Evidence Based Approach for the Diagnosis of Temporomandibular Joint Disorders (TMD). J. Indian Prosthodont. Soc. 2013, 13, 387-388. [CrossRef]

6. Ott, K.H. Diagnosis and therapy of masseter hypertrophy. HNO 1983, 31, 207-211. [PubMed]

7. Cheng, H.Y.; Peng, P.W.; Lin, Y.J.; Chang, S.T.; Pan, Y.N.; Lee, S.C.; Ou, K.L.; Hsu, W.C. Stress analysis during jaw movement based on vivo computed tomography images from patients with temporomandibular disorders. Int. J. Oral Maxillofac. Surg. 2013, 42, 386-392. [CrossRef] [PubMed]

8. Kurita, K.; Westesson, P.-L.; Yuasa, H.; Toyama, M.; Machida, J.; Ogi, N. Natural Course of Untreated Symptomatic Temporomandibular Joint Disc Displacement without Reduction. J. Dent. Res. 1998, 77, 361-365. [CrossRef] [PubMed]

9. Kalpakci, K.N.; Willard, V.P.; Wong, M.E.; Athanasiou, K.A. An Interspecies Comparison of the Temporomandibular Joint Disc. J. Dent. Res. 2011, 90, 193-198. [CrossRef] [PubMed]

10. Pereira, L.J.; Steenks, M.H.; de Wijer, A.; Speksnijder, C.M.; van der Bilt, A. Masticatory function in subacute TMD patients before and after treatment. J. Oral Rehabil. 2009, 36, 391-402. [CrossRef]

11. Durham, J.; Steele, J.; Moufti, M.A.; Wassell, R.; Robinson, P.; Exley, C. Temporomandibular disorder patients' journey through care. Community Dent. Oral 2011, 39, 532-541. [CrossRef] [PubMed]

12. Kou, W.; Gareus, I.; Bell, J.D.; Goebel, M.U.; Spahn, G.; Pacheco-Lopez, G.; Backer, M.; Schedlowski, M.; Dobos, G.J. Quantification of DeQi sensation by visual analog scales in healthy humans after immunostimulating acupuncture treatment. Am. J. Chin. Med. 2007, 35, 753-765. [CrossRef] [PubMed]

13. Liang, Z.H.; Xie, C.C.; Li, Z.P.; Zhu, X.P.; Lu, A.P.; Fu, W.B. Deqi sensation in placebo acupuncture: A crossover study on Chinese medicine students. Evid. Based Complement. Altern. Med. 2013, 2013, 620671. [CrossRef] [PubMed]

14. Zhang, S.; Mu, W.; Xiao, L.; Zheng, W.K.; Liu, C.X.; Zhang, L.; Shang, H.C. Is deqi an indicator of clinical efficacy of acupuncture? A systematic review. Evid. Based Complement. Altern. Med. 2013, 2013, 750140. [CrossRef]

15. Park, J.; Park, H.; Lee, H.; Lim, S.; Ahn, K.; Lee, H. Deqi sensation between the acupuncture-experienced and the naive: A Korean study II. Am. J. Chin. Med. 2005, 33, 329-337. [CrossRef]

16. Yang, X.Y.; Shi, G.X.; Li, Q.Q.; Zhang, Z.H.; Xu, Q.; Liu, C.Z. Characterization of deqi sensation and acupuncture effect. Evid. Based Complement. Altern. Med. 2013, 2013, 319734. [CrossRef] [PubMed]

17. Langevin, H.M.; Churchill, D.L.; Wu, J.; Badger, G.J.; Yandow, J.A.; Fox, J.R.; Krag, M.H. Evidence of connective tissue involvement in acupuncture. FASEB J. 2002, 16, 872-874. [CrossRef]

18. Langevin, H.M.; Storch, K.N.; Snapp, R.R.; Bouffard, N.A.; Badger, G.J.; Howe, A.K.; Taatjes, D.J. Tissue stretch induces nuclear remodeling in connective tissue fibroblasts. Histochem. Cell Biol. 2010, 133, 405-415. [CrossRef]

19. Langevin, H.M. Connective tissue: A body-wide signaling network? Med. Hypotheses 2006, 66, $1074-1077$. [CrossRef]

20. Langevin, H.M.; Churchill, D.L.; Cipolla, M.J. Mechanical signaling through connective tissue: A mechanism for the therapeutic effect of acupuncture. FASEB J. 2001, 15, 2275-2282. [CrossRef] 
21. Langevin, H.M.; Bouffard, N.A.; Fox, J.R.; Palmer, B.M.; Wu, J.; Iatridis, J.C.; Barnes, W.D.; Badger, G.J.; Howe, A.K. Fibroblast cytoskeletal remodeling contributes to connective tissue tension. J. Cell Physiol. 2011, 226, 1166-1175. [CrossRef] [PubMed]

22. Joshi, N.; Araque, H. Neurophysiologic basis for the relief of human pain by acupuncture. Acupunct. Electrother. Res. 2009, 34, 165-174. [CrossRef] [PubMed]

23. Hui, K.K.; Nixon, E.E.; Vangel, M.G.; Liu, J.; Marina, O.; Napadow, V.; Hodge, S.M.; Rosen, B.R.; Makris, N.; Kennedy, D.N. Characterization of the "deqi" response in acupuncture. BMC Complement. Altern Med. 2007, 7, 33. [CrossRef] [PubMed]

24. Yim, E.K.; Darling, E.M.; Kulangara, K.; Guilak, F.; Leong, K.W. Nanotopography-induced changes in focal adhesions, cytoskeletal organization, and mechanical properties of human mesenchymal stem cells. Biomaterials 2010, 31, 1299-1306. [CrossRef]

25. Liu, X. Correlation analysis of surface topography and its mechanical properties at micro and nanometre scales. Wear 2013, 305, 305-311. [CrossRef]

26. Arsiwala, A.; Desai, P.; Patravale, V. Recent advances in micro/nanoscale biomedical implants. J. Controll. Release 2014, 189, 25-45. [CrossRef]

27. Saber, O.; Hefny, N.; al Jaafari, A.A. Improvement of physical characteristics of petroleum waxes by using nano-structured materials. Fuel Process. Technol. 2011, 92, 946-951. [CrossRef]

28. Martinez, E.; Engel, E.; Planell, J.A.; Samitier, J. Effects of artificial micro- and nano-structured surfaces on cell behavior. Ann. Anat. Anat. Anz. 2009, 191, 126-135. [CrossRef] [PubMed]

29. Andersson, A.S.; Backhed, F.; von Euler, A.; Richter-Dahlfors, A.; Sutherland, D.; Kasemo, B. Nanoscale features influence epithelial cell morphology and cytokine production. Biomaterials 2003, 24, 3427-3436. [CrossRef]

30. Dalby, M.J.; McCloy, D.; Robertson, M.; Agheli, H.; Sutherland, D.; Affrossman, S.; Oreffo, R.O.C. Osteoprogenitor response to semi-ordered and random nanotopographies. Biomaterials 2006, 27, $2980-2987$. [CrossRef] [PubMed]

31. Dalby, M.J.; Gadegaard, N.; Tare, R.; Andar, A.; Riehle, M.O.; Herzyk, P.; Wilkinson, C.D.; Oreffo, R.O. The control of human mesenchymal cell differentiation using nanoscale symmetry and disorder. Nat. Mater. 2007, 6, 997-1003. [CrossRef] [PubMed]

32. Dalby, M.J.; Gadegaard, N.; Oreffo, R.O. Harnessing nanotopography and integrin-matrix interactions to influence stem cell fate. Nat. Mater. 2014, 13, 558-569. [CrossRef] [PubMed]

33. Bachmann, J.; Ellies, A.; Hartge, K.H. Development and application of a new sessile drop contact angle method to assess soil water repellency. J. Hydrol. 2000, 231, 66-75. [CrossRef]

34. Maier, C.; Baron, R.; Tolle, T.R.; Binder, A.; Birbaumer, N.; Birklein, F.; Gierthmuhlen, J.; Flor, H.; Geber, C.; Huge, V.; et al. Quantitative sensory testing in the German Research Network on Neuropathic Pain (DFNS): Somatosensory abnormalities in 1236 patients with different neuropathic pain syndromes. Pain 2010, 150, 439-450. [CrossRef]

35. Rolke, R.; Baron, R.; Maier, C.; Tolle, T.R.; Treede, R.D.; Beyer, A.; Binder, A.; Birbaumer, N.; Birklein, F.; Botefur, I.C.; et al. Quantitative sensory testing in the German Research Network on Neuropathic Pain (DFNS): Standardized protocol and reference values. Pain 2006, 123, 231-243. [CrossRef]

36. Pigg, M.; Baad-Hansen, L.; Svensson, P.; Drangsholt, M.; List, T. Reliability of intraoral quantitative sensory testing (QST). Pain 2010, 148, 220-226. [CrossRef]

37. Drelich, J.; Chibowski, E.; Meng, D.D.; Terpilowski, K. Hydrophilic and superhydrophilic surfaces and materials. Soft Matter 2011, 7, 9804-9828. [CrossRef]

38. Takeshige, C.; Sato, M. Comparisons of pain relief mechanisms between needling to the muscle, static magnetic field, external qigong and needling to the acupuncture point. Acupunct. Electrother. Res. 1996, 21, 119-131. [CrossRef]

39. Karst, M.; Rollnik, J.D.; Fink, M.; Reinhard, M.; Piepenbrock, S. Pressure pain threshold and needle acupuncture in chronic tension-type headache-a double-blind placebo-controlled study. Pain 2000, 88, 199-203. [CrossRef]

40. Orhan, E.K.; Deymeer, F.; Oflazer, P.; Parman, Y.; Baslo, M.B. Jitter analysis with concentric needle electrode in the masseter muscle for the diagnosis of generalised myasthenia gravis. Clin. Neurophysiol. 2013, 124, 2277-2282. [CrossRef] 
41. Itoh, K.; Minakawa, Y.; Kitakoji, H. Effect of acupuncture depth on muscle pain. Chin. Med. 2011, 6, 24. [CrossRef] [PubMed]

42. Ulett, G.A. Acupuncture treatments for pain relief. JAMA 1981, 245, 768-769. [CrossRef] [PubMed]

43. Asghar, A.U.; Green, G.; Lythgoe, M.F.; Lewith, G.; MacPherson, H. Acupuncture needling sensation: The neural correlates of deqi using fMRI. Brain Res. 2010, 1315, 111-118. [CrossRef] [PubMed]

44. Langevin, H.M.; Yandow, J.A. Relationship of acupuncture points and meridians to connective tissue planes. Anat. Rec. 2002, 269, 257-265. [CrossRef] [PubMed]

45. Langevin, H.M.; Storch, K.N.; Cipolla, M.J.; White, S.L.; Buttolph, T.R.; Taatjes, D.J. Fibroblast spreading induced by connective tissue stretch involves intracellular redistribution of alpha- and beta-actin. Histochem. Cell Biol. 2006, 125, 487-495. [CrossRef] [PubMed]

46. Eadie, M.J. Acupuncture and the relief of pain. Med. J. Aust. 1990, 153, 180-181. [CrossRef]

47. Seminowicz, D.A. Acupuncture and the CNS: What can the brain at rest suggest? Pain 2008, 136, $230-231$. [CrossRef]

48. Rong, P.J.; Zhu, B.; Huang, Q.F.; Gao, X.Y.; Ben, H.; Li, Y.H. Acupuncture inhibition on neuronal activity of spinal dorsal horn induced by noxious colorectal distention in rat. World J. Gastroenterol. 2005, 11, 1011-1017. [CrossRef]

49. Woolf, C.J.; Salter, M.W. Neuronal Plasticity: Increasing the Gain in Pain. Science 2000, 288, 1765-1768. [CrossRef] [PubMed]

50. Melzack, R. Evolution of the Neuromatrix Theory of Pain. The Prithvi Raj Lecture: Presented at the Third World Congress of World Institute of Pain, Barcelona 2004. Pain Pract. 2005, 5, 85-94. [CrossRef]

51. Mao, J.J.; Rahemtulla, F.; Scott, P.G. Proteoglycan Expression in the Rat Temporomandibular Joint in Response to Unilateral Bite Raise. J. Dent. Res. 1998, 77, 1520-1528. [CrossRef] [PubMed]

52. Berkovitz, B.K.B.; Robertshaw, H. Ultrastructural quantification of collagen in the articular disc of the temporomandibular joint of the rabbit. Arch. Oral Biol. 1993, 38, 91-95. [CrossRef]

53. Liu, M.; Tanswell, A.K.; Post, M. Mechanical force-induced signal transduction in lung cells. Am. J. Physiol. Lung Cell. Mol. Physiol. 1999, 277, L667-L683. [CrossRef] [PubMed]

54. Cope, F.W. Piezoelectricity and pyroelectricity as a basis for force and temeprature detection by nerve receptors. Bull. Math. Biol. 1973, 35, 31-41. [CrossRef]

55. Yamanishi, T.; Yasuda, K. Electrical stimulation for stress incontinence. Int. Urogynecol. J. 1998, 9, $281-290$. [CrossRef] [PubMed]

56. Chiquet, M. Regulation of extracellular matrix gene expression by mechanical stress. Matrix Biol. 1999, 18, 417-426. [CrossRef]

(C) 2020 by the authors. Licensee MDPI, Basel, Switzerland. This article is an open access article distributed under the terms and conditions of the Creative Commons Attribution (CC BY) license (http://creativecommons.org/licenses/by/4.0/). 